\title{
ĐĂC ĐIỂM HÌNH ẢNH CộNG HƯởNG TỪ NÃO, MẠCH MÁU NÃO TRÊN ĐỐI TƯợNG KHÁM SỨC KHỎE ĐỊNH KỲ TẠI BÊ̂NH VIỆN TRUNG ƯO'NG QUÂN ĐộI 108
}

\section{TÓM TẮT}

Cộng hưởng từ 3.0 tesla sọ não có khả năng phát hiện những bất thường trong nhu mô cũng như mạch máu não như: u não, teo não, thoái hóa chất trắng, nhồi máu não, phình động mạch não, dị dạng động tĩnh mạch não, hẹp, tắc mạn tính mạch máu não... ngay từ khi chưa có triệu chứng lâm sàng. Chính vì vậy, rất có ý nghĩa trong điêuu trị dự phòng đột quy. Chúng tôi tiến hành khảo sát hình ảnh cộng hưởng từ 3.0 tesla sọ não, mạch máu não trên 184 người khỏe mạnh khám sức khỏe định kỳ tại Bệnh viện Trung ưởng Quân đội 108. Mục tiêu: Xác định những bệnh lý não và mạch máu nã̃o được phát hiện ngâuu nhiên trên hình ảnh cộng hưởng từ sọ não (MRI). Phương pháp: nghiên cứu tiến cứu, mô tả cắt ngang trên đối tượng 184 người đến khám sức khỏe định kỳ được chụp MRI 3.0 tesla sọ não và mach mạch máu não. Kểt quả: Tỷ lệ những bệnh lý được phát hiện ngẫu nhiên trên MRI so não $3.0 T$ là $9,7 \%$. Trong đó nhồi máu não cũ 1 người $(0,5 \%)$; phình mạch não 4 người $(2,2 \%)$; u nang màng nhện 01 người $(0,5 \%)$; thoái hóa chất trắng 11 người (chiếm $5,9 \%$ ), hẹp mach máu não 01 người $(0,5 \%)$. Kêt luận: Phát hiện ngẫu nhiên trên cộng hưởng từ sọ não 3.0T các trường hợp phình mạch não, hẹp động mach não, nhồi máu não không triệu chứng... những phát hiện nàyrất có ý nghĩa trong điểu trị dự phòng đột quy.

Tứ khóa: Nhồi máu não không triệu chứng, phình mach não.

\section{SUMMARY \\ CHARACTERISTICS OF BRAIN MAGHETIC RESONANCE IMAGING AND MAGNETIC

Brainmagnetic resonance imaging (MRI) and magnetic resonance angiography (MRA) can detect brain anomalies and cerebrovascular anomalies such as brain tumors, atrophy, awhite-matter lesions, asymptomatic brain infarcts, aneurysms, arteriovenous malformations, occlusion or stenosis of cerebrovascular... and subclinical vascular pathologic changes. It is very important for stroke prevention. We conducted a analyzed brain 3.0 teslaMRI, MRA

*Bệnh viện TWQD 108

Chiu trách nhiệm chính: Nguyễn Văn Tuyến

Email: bstuyena21@gmail.com

Ngày nhận bài: 2/10/2021

Ngày phản biên khoa họ: 29/10/2021

Ngày duyệt bài: 11/11/2021
Nguyễn Văn Tuyến*, Lê Vương Quý*

from 184 peoplewho underwent periodic health examination in 108 Military Central Hospital. Objective: To quantify the prevalence of incidental findings onMRI, MRA of the brain. Method: Prospective observational study from 184 people who underwent brain 3.0 teslaMRI, MRA. Results: Incidental intracranial findings were present in 9,7\%. Asymptomatic cerebral infarction were present in 1 persons (0,5\%); Cerebral aneurysm (2,2\%) and arachnoid cyst $(0,5 \%)$, in total 11 persons had excessive white matter hyperintensities (WMH) $(5,9 \%)$. Conclusions: Incidental brain findings on MRI and MRA includingcerebral aneurysms, stenosis cerebrovascular, asymptomatic brain infarcts...These detectionsare very useful to prevent stroke.

Keyword: Asymptomatic brain infarcts, cerebral aneurysms.

\section{I. ĐĂT VẤN ĐỀ}

Đột quỵ não là nguyên nhân gây tử vong thứ 2 thể giới, đứng đầu ở các quốc gia thu nhập trung bình, đột quy. não có xu hướng trẻ hóa và tăng ở các quốc gia thu nhập thấp, và ngưỡng trung bình thấp trong đó có Việt Nam. Trên thế giới mỗi 1 năm có 16 triệu ca mắc mới, 6 triệu ca tử vong (Stephen Davis, 2012). Tại Mỹ, 40 giây/người mắc mới, 4 phút/1 người tử vong do đột quy não (Mozaffarian, 2016). Dự báo tới năm 2030 tỷ lệ đột quy não tăng thêm $20,5 \%$ so với 2012 (American Heart Association, 2013). Theo tính toán thì mỗi lần đột quy. não giảm tới 43 năm tuổi thọ, gần $90 \%$ bệnh nhân đột quỵ để lại khuyết tật, sống phải nhờ vào sự chăm sóc của gia đình và xã hội, chỉ có khoảng $10 \%$ hồi phục trở lại với công việc ban đầu (Ovbiagele,2013). Như vậy, tìm ra các biện pháp điều trị dự phòng nhằm giảm tỷ lệ bệnh nhân đột quylà rấtquan trọng. Ngày nay nhờ khoa học phát triển, chúng ta cũng có những phương tiện chẩn đoán hình ảnh hiện đại như cộng hưởng từ 3.0 Tesla, máy chụp cắt lớp vi tính đa dãy, máy chụp mạch máu não số hóa xóa nền... có thể khảo sát được tình trạng các dị dạng mạch máu nội sọ hay tình trạng vữa sơ gây hẹp, tắc để từ đó có biện pháp can thiệp sớm, dự phòng đột quy.

Xuất phát từ vấn đề đó chúng tôi tiến hành nghiên cứu này nhằm phát hiện bất thường trên hình ảnh cộng hưởng từ sọ não gồm cả mạch máu não được phát hiện ngẫu nhiên trên cộng hưởng từ 3.0T ở những người tiền sử người khỏe 
mạnh. Từ đó có những khuyến cáo trong chỉ định, lực chọn phương tiện chẩn đoán, kiểm tra sức khoẻ dự phòng đột quy. não.

\section{II. ĐỐI TƯỢNG VÀ PHƯƠNG PHÁP NGHIÊN CỨU}

2.1. Đối tượng nghiên cứu: 184 người trưởng thành khỏe mạnh được tiến hànhkiểm tra sức khỏe, chụp MRI sọ não. Hình ảnh cộng hưởng từ được thu thập từ 184 người trưởng thành vào tháng $6 / 2018$.

\subsection{Phương pháp nghiên cứu}

2.2.1. Thiết kế nghiên cứu: Nghiên cứu mô tả cắt ngang.

\subsubsection{Nôi dung nghiên cứu}

- Tất cả các bệnh nhân được chụp cộng hưởng từ 3.0T theo giao thức chuẩn hóa bao gồm bốn chuỗi xung có độ phân giải cao: T1W, T2W, T2 FLAIR, T2*, xung mach TOF.

- Tất cả các phim MRI sọ não đều được đánh giá bởi 02 bác sĩ. Một bác sĩ Xquang, một bác sĩ thần kinh có kinh nghiêm.

- Các tổn thương phát hiện ngẫu nhiên

+ Nang màng nhện.

+ Bất thường mạch não: phình mạch não, di dạng thông động tînh mạch, u mạch thể hang (cavernome),hẹp tắc động mạch não...

+ U não.

+ Nhồi máu não.

+ Thoái hóa chất trắng.

2.2.3. Thu thập và xử lý số liệu: Bằng phần mềm SPSS 18.0

\section{KẾT QUẢ NGHIÊN CỨU}

Bảng 1.Tuổi trung binh của nhóm đối tượng nghiên cứu

\begin{tabular}{|c|c|}
\hline & Tuối trung bình \pm độ lệch chuấn \\
\hline Nam & $47,8 \pm 13,78$ \\
\hline Nữ & $47,5 \pm 13,85$ \\
\hline Chung & $47,8 \pm 13,79$ \\
\hline
\end{tabular}

Bảng 2. Phân giới của nhóm đổi tượng nghiên cứu

\begin{tabular}{|c|c|}
\hline Giới & Số lượng (n, \%) \\
\hline Nam & $136(73,9)$ \\
\hline Nữ & $48(26,1)$ \\
\hline
\end{tabular}

\section{กล̃o}

Bảng 3. Tôn thương phát hiện trên MRI sọ

\begin{tabular}{|c|c|}
\hline \multicolumn{2}{|c|}{$\begin{array}{l}\text { Tỷ lệ hình ảnh phát hiên ngấu nhiên trên cộng } \\
\text { hưởng từ sọ não 3̇.0T của bệnh nhân }\end{array}$} \\
\hline $\begin{array}{c}\text { Hình ảnh phát hiện ngâu nhiên } \\
\text { trên MRI sọ não }\end{array}$ & $\mathrm{n}(\%)$ \\
\hline Nhồi máu não không triêu chứng & $1(0,5)$ \\
\hline \multicolumn{2}{|c|}{ Các phát hiện bất thường khác } \\
\hline Phình động mạch não & $4(2,2)$ \\
\hline Hẹp mạch não & $1(0,5)$ \\
\hline Thoái hóa chất trắng & $11(5,9)$ \\
\hline
\end{tabular}

\begin{tabular}{|c|c|}
\hline Nang màng nhện & $1(0,5)$ \\
\hline Thiếu sản động mạch & $11(5,9)$ \\
\hline Viêm xoang & $57(30,9)$ \\
\hline $\begin{array}{c}\text { Tỷ lệ phát hiên hình ảnh ngâu } \\
\text { nhiên chung }\end{array}$ & $18(0,9)$ \\
\hline
\end{tabular}

Tuối trung bình của 184 đối tượng nghiên cứu là 47 tuổi (dao động từ 28 tuổi đến 86 tuổi). Trong đó, 136 người là nam (chiếm 73,9\%). Trong 184 người tham gia nghiên cứu có 166 (chiếm 90,3\%) người có hình ảnh MRI sọ não bình thường. Tất cả đối tượng nghiên cứu đều không ghi nhận được bất kỳ triệu chứng nào liên quan tới bệnh lý thuộc não ngoại trừ 01 trường hợp bệnh nhân đặt stent cảnh trong trái cách 9 tháng. Tất cả các bất thường được phát hiện ngẫu nhiên trên cộng hưởng từ chiếm 18/184 $(9,7 \%)$, trong đó có 05 người cần theo dõi tiếp tục trên lâm sàng. Cộng hưởng từ não ghi nhận hình ảnh hẹp tại vị trí ngã 3 động mạch cảnh trong trái tại vị trí phân chia động mạch não giữa, não trước trái. Phát hiện hình ảnh nhồi máu não ổ khuyết không triệu chứng ở 01 người. Hình ảnh phình mạch não phát hiện ở 04 người chiếm $(2,2 \%) .01$ phình động mạch cảnh trong trái đoạn xoang hang, 03 phình động mạch cảnh trong phải đoạn Siphone, với kích thước cổ túi phình lớn nhất là $2,3 \mathrm{~mm}$, kích thước túi phình trung bình khoảng 2,8 x 2,3mm.04 bệnh nhân phình động mạch não có nguy cơ vỡ thấp nên đang được theo dõi sát. 01 bệnh nhân hẹp động mạch đã được điều trị đặt stent. 01 người có nang màng nhện cạnh não thất bên bên phải. Thoái hóa chất trắng gặp ở 11 người. Bên cạnh đó, có 57 (chiếm 30,9\%) người có viêm xoang (chủ yếu viêm xoang hàm, xoang sàng, một số ít viêm xoang trán, xoang bướm), 14 người có hình ảnh động mạch não thiểu sản hoặc khuyết một động mạch so với giải phẫu chuẩn. Không có sự khác biệt về tuổi, giới ở nhóm phát hiện tổn thương ngẫu nhiên trên MRI sọ não.

\section{BÀN LUẬN}

Trong nghiên cứu về các phát hiện ngẫu nhiên trong hình ảnh MRI sọ não của các đối tượng khỏe mạnh, chúng tôi đã xác định được các bất thường là khá phổ biến, với tỳ lệ $9,7 \%$ (không bao gồm bệnh nhân phát hiện tổn thương viêm xoang). Trong nghiên cứu của Gur và cộng sự (2013) nghiên cứu trên 1400 người có tuổi từ 8-23, được khảo sát bằng MRI so $3.0 T$ ghi nhận tỷ lệ các phát hiện ngẫu nhiên chiếm 10,6\% tương tự kết quả nghiên cứu của chúng tôi[3].

Nhiều dữ liệu nghiên cứu trước đây cung cấp 
các thông tin liên quan tới tỷ lệ các phát hiện ngẫu nhiên ở các quần thể không đồng nhất.Nghiên cứu có quy mô lớn đầu tiên trên 1000 tình nguyện viên không có triệu chứng (độ tuổi 3-83) đã báo cáo tỷ lệ phát hiện ngẫu nhiên là 4,8\%. Hầu hết các nghiên cứu đều báo cáo tỷ lệ không bao gồm bệnh lý xoang. Kim và cộng sự (2002), nghiên cứu trên 225 đối tượng khỏe mạnh, không bệnh lý về thần kinh đã xác định tỷ lệ phát hiện ngẫu nhiên khoảng $11 \%$, thường ở nam giới với tỷ lệ nam/ nữ $=2 / 1$ (6). Seki và cộng sự (2010) đã đánh giáở 110 trẻ em khỏe mạnh (5-8 tuổi) ghi nhận có tỷ lệ phát hiện ngẫu nhiên chiếm $11 \%$. Một phân tích tổng hợp của 16 nghiên cứu bao gồm gần 20.000 lần quét, chủ yếu ở người trưởng thành, đã báo cáo kết quả ngẫu nhiên không nhất quán và thây rằng tỷ lệ phát hiện ngẫu nhiên có liên quan đến độ phân giải hình ảnh.

- Nhồi máu não không triệu chứng: Trong nghiên cứu của chúng tôi, không sử dụng cộng hưởng từ tiêm đối quang từ vì các đối tượng nghiên cứu là người khỏe mạnh không có triệu chứng thần kinh khu trú. Một số nghiên cứu ghi nhận, khi sử dụng cộng hưởng từ không tiêm đối quang từ, sẽ có một số tổn thương nhỏ sẽ không được phát hiện và có thể làm cho tỷ lệ phát hiện tổn thương ngẫu nhiên thấp hơn thực tế. Tuy nhiên, với MRI 3.0T, và với chương trình chụp đặc biệt dành cho sọ não thì tỷ lệ này rất thấp, gẩn như không ảnh hưởng tới tỷ lể phát hiện tổn thương ngẫu nhiên trên MRI sọ não.

Susanne và cộng sự (2004), ghi nhận tỷ lệ nhồi máu não không triệu chứng chiếm $0,6 \%$. Tỷ lệ này tương tự nghiên cứu của chúng tôi. Điều này có thể do sự tương đồng về đối tượng nghiên cứu đặc biệt là tuổi trung bình. Một số nghiên cứu khác, tỷ lệ nhồi máu não không triệu chứng thường chiếm tỷ lệ cao hơn và tăng theo nhóm tuổi. Theo Vernooij (2007), tỷ lệ nhồi máu não không triệu chứng chiếm $7,2 \%$ với tuổi trung bình là 64 tuổivà tỷ lệ này tăng theo tuổi. Ở nhóm tuổi từ 75 đến 97 có $18,3 \%$ nhồi máu não không triệu chứng. Tỷ lệ nhồi máu não không triệu chứng trong nghiên cứu của chúng tôi thấp hơn so với nhiều nghiên cứu khác ở nước ngoài.Điều này có thể giải thích do đối tượng của nghiên cứu chủ yếu là người khỏe mạnh đang công tác, ít có các yếu tố nguy cơ kèm theo (02 người có bệnh lý tăng huyết áp, 01 người có tắc động mạch cảnh đã đặt stent). Das và cộng sự (2008), tỷ lệ nhồi máu não không triệu chứng dao động khoảng 5,8\% đến $28 \%$. Tỷ lệ này dao động phụ thuộc vào tuổi, giới, các yếu tố nguy cơ như tăng huyết áp, đái tháo đường typ II, hút thuốc lá, rối loạn mõ̃ máu, bệnh lý tim mạch kèm theo cũng như kỹ thuật chụp MRI [1].

- Phinh mạch não: Trong nghiên cứu của chúng tôi, tỷ lệ bệnh lý mạch máu não phát hiện ngẫu nhiên khi chụp MRI sọ não cao hơn so với các nghiên cứu trước đây. Trong nghiên cứu phân tích tổng hợp, tỷ lệ phình mạch não phát hiện ngẫu nhiên chiếm 0,67\% (Morris, 2009). Theo Vernooij và cộng sự (2007), tỷ lệ phình mạch não phát hiện ngẫu nhiên chiếm $1,8 \%$, và phân bố đều ở các tuổi từ 45-59, từ 60-74 và từ 75-95. Theo (Håberg (2016)), tỳ lệ này tăng lên 2,3\%. Theo Yue, 1997 ghi nhận tỷ lệ phình mạch não chiếm 0,11\% ở những người trền 65 tuổi[8]. Theo nghiên cứu của Morris và cộng sự (1997) ghi nhận tỷ lệ phình động mạch não ở các nghiên cứu dựa trên khám nghiệm tử thi thường thấp hơn các nghiên cứu dựa trên chụp động mạch não. Kết quả của chúng tôi ghi nhận tỷ lệ phát hiện ngẫu nhiên phình mạch não là $2,2 \%$ và thuộc nhóm tuổi 42-59. Kết quả của chúng tôi có cao hơn so với các nghiên cứu khác, sự khác biệt này có thể được giải thích do việc sử dụng các kỹ thuật tiên tiến và chương trình toàn diện với độ phẩn giải cao của MRI sọ não 3.0T làm tăng độ nhạy phát hiện các bất thường, đặc biệt là bất thường mạch. Một lý do nữa mà được nhiều nghiên cứu đề cập đến đó là người đọc kết quả phim chụp. Đối với nghiên cứu có sự tham gia của bác sĩ thần kinh hoặc những chuyên gia hình ảnh học có kinh nghiệm về bệnh lý ở não khi đọc hoặc kiểm tra kết quả cộng hưởng từ so não, thông thường tỷ lệ phát hiện những bất thường sẽ cao hơn. Nhận định này đã được Illes và cộng sự công bố năm 2004 trong nghiên cứu của mình. Rinkel và cộng sự (1998) nghiên cứu nhận định tỷ lệ phình mạch não có thể tìm thấy ở $2 \%$ số người mà không có nguy cơ vỡ gây chảy máu dưới nhện. Hướng dẫn về việc quản lý, theo dõi các phình động mạch não nhóm đã được đưa ra. Hơn $90 \%$ phình động mạch não khồng võ, không có có triệu chứng được phát hiện qua khám nghiêm tử thi hoạc chụp động mạch. Đường kính của phình mạch thường dưới $10 \mathrm{~mm}$. Trong nghiên cứu của chúng tôi, tất cả các độ $10 \mathrm{~mm}$ và thuộc tuần hoàn não trước. Theo Wiebers DO và cộng sự (2003) báo cáo ghi nhận với các phình mạch có kích thước như vậy nguy cơ võ̃ trong 4 năm là $0 \%$ ở những người có tiên sử gia đình liên quan tới phình mạch não (tiền sử gia đình có người bị phình mạch não hoặc những người có triệu chứng bất kỳ, đi 
khám và phát hiện phình mạch chưa võ). Và như vậy, nguy cơ vớ liên quan tới phình mạch chưa vỡ, không triệu chứng có thể còn thấp hơn khi so sánh với đối tượng trong nghiên cứu của Wiebers DO[9].

- Nang màng nhện: Robinson và cộng sự công bố (1971) rằng u nang màng nhện tương đối hiếm gặp và chiếm khoảng $1 \%$ khối bất thường nội sọ. Trong nghiên cứu của Katzman và cộng sự (1999) tỷ lệ này là $0,3 \%$. Vernooij và cộng sự (2007) tỷ lệ u nang màng nhện là 1,1\%; Håberg (2016) tỷ lệ u nang màng nhện là 3,6\%[4]. Tỷ lệ u nang màng nhện trong nghiên cứu của chúng tôi là $0,5 \%$.Sự khác nhau này có thể được giải thích do khác nhau về đối tượng nghiên cứu.

- Thoái hóa chất trắng: Tỷ lệ thoái hóa chất trắng phát hiện trên MRI sọ não trong nghiên cứu của chúng tôi chiếm $5,9 \%$. Theo Håberg và cộng sư (2016) ghi nhận tỳ lệ này chiếm 9\%[4].

- Viêm xoang: Tỷ lệ viêm xoang được phát hiện trên hình ảnh MRI sọ não trong nghiên cứu của chúng tôi là $30,9 \%$. Các nghiên cứu ghi nhận tỷ lệ phát hiện ngẫu nhiên viêm xoang dao động 13,2\% đến 49,2\% (Katzman và cộng sự (1999)). Tỷ lệ này thay đổi tùy từng nghiên cứu. Có ý kiến cho rằng sự khác nhau là do đối tượng nghiên cứu và thời gian tiến hành nghiên cứu trong năm.

Đột quy não (hay tai biến mạch máu não) về bản chất là bệnh lý mạch máu não.Việc tầm soát phát hiện các bất thường mạch máu não để điều trị từ trước khi đột quy xảy ra và việc làm cân thiết và rất quan trọng để giảm tỷ lệ đột quy não tiên phát. Theo các báo cáo thống kề tỳ lệ đột quỵ não tại các quốc gia phát triển như Pháp, Thụy Điển,Na Uy... tỷ lệ đột quy có xu hướng giảm dần trong những năm gần đây. Tuy nhiên, tại các quốc gia đang phát triển lại có xu hướng tăng hơn. Điều này chính là nhờ việc điêu trị và dự phòng tốt các yếu tố nguy cơ có thể thay đổi được và điêu trị ban đâu các bất thường mạch máu não gây nển đột quy não.Chúng ta còn rất ít quan tâm đến tình trạng mach máu não khi kiểm tra sức khoẻ. Trên thực tế rất nhiều bệnh nhân khi đã bị đột quy rồi, vào viện chụp mạch máu não chúng ta mới thấy các tổn thương hẹp,dị dạng thông động - tĩnh mạch não, phồng động mạch não, u máu thể hang... Nếu như các bệnh nhân này được chụp cộng hưởng từ não, mạch não từ trước, thì hoàn toàn chúng ta có thể đã có biên pháp điều trị dự phòng hiệu quả. Như vậy, với một chi phí không lớn, không phải tiêm thuốc cản quang chụp MRI não mạch não cho ta biết khá nhiêu thông tin đặc biệt là tình trạng mạch máu não. Vấn đề này rất cần được quan tâm khi các bác sỹ khám sàng lọc nguy cơ đột quy. não.

\section{KẾT LUẦN}

Qua khảo sát phim cộng hưởng từ 3.0 tesla so não ở 184 người khám kiểm tra sức khỏe định kỳ tại Bênh viên Trung ương Quân đôi 108 chúng tôi nhận thấy: Phình mạch não chiếm tỷ lệ 2,2\%; Hẹp mạch não chiếm tỷ lệ 0,5\%; Thiểu sản đông mach não chiếm tỷ lệ 5,9\%.; Nhồi máu não không triệu chứng chiếm tỷ lệ $0,5 \%$; Thoái hóa chất trắng chiếm $5,9 \%$.

Nhữngphát hiện ngấu nhiên trên cộng hưởng từ so não 3.0T các trường hợp phình mạch não, hẹp động mach não, nhồi máu não khổng triệu chứng... là những phát hiện rất có ý nghĩa trong điều trị dự phòng đột quy. Kết quả này ghi nhận có thể sử dụng MRI sọ não để sàng lọc các bệnh lý não, mạch máu não trong tương lai. Tuy nhiên, đây cũng chỉ là nghiên cứu trên số lượng bệnh nhân hạn chế đến khám tại Bệnh viện Trung ương Quân đội 108 không đại diện được cho cộng đồng.

\section{TÀI LIỆU THAM KHẢO}

1. Das RR, Seshadri S, Beiser AS., (2008) "Prevalence and correlates of silent cerebral infarcts in the Framingham offspring study",Stroke, 39(11), pp.2929- 35.

2. Illes, J., Kirschen, M. P., Karetsky., (2004), Discovery and disclosure of incidental findings in neuroimaging research",Journal of Magnetic Resonance Imaging, 20(5), pp.743-747.

3. Gur R.E., Kaltman D., Melhem E.R., (2013), " Incidental Findings in Youths Volunteering for Brain MRI Research", American Journal of Neuroradiology, 34 (10), pp. 2012-5

4. Håberg, (2016), "Incidental Intracranial Findings and Their Clinical Impact; The HUNT MRI Study in a General Population of 1006 Participants between 50-66 Years", iMedPub Journals

5. Robinson RG, (1971), "Congenital cysts of the brain: arachnoid malformations", Prog Neurol Surg; 4, pp.133-174

6. Kim BS, Illes J, Kaplan RT., (2002), "Incidental findings on pediatric MR images of the brain", AJNR Am J Neuroradiol, 23, pp.1674-77

7. Rinkel., (1998), "Prevalence and risk of rupture of intracranial aneurysms: a systematic re-view", Stroke, 29, pp.251-6

8. Yue NC, Longstreth WT Jr, Elster AD., (1997) "Clinically serious abnormalities found incidentally at MR imaging of the brain", data from the Cardiovascular Health Study. Radiology, 202, pp. 41-6. 